\title{
Initial low frequency vibrations of the first heart sound ${ }^{1}$
}

\author{
T. G. Armstrong and M. S. Gotsman \\ From the Cardiac Unit, Department of Medicine, Wentworth Hospital and the University of Natal \\ South Africa
}

The low frequency, earliest component of the first heart sound ' $M$ ' was studied in 53 subjects. It is present in normal subjects and in patients in whom prosthetic replacement of one or both atrioventricular valves have been undertaken whether they are in sinus rhythm or in atrial fibrillation. After prosthetic valve replacement ' $M$ ' is often accentuated. ' $M$ ' is not caused by atrial activity, tricuspid valve closure, or valve cusp coaption. It corresponds to the initial movement of the apical ventricular impulse and is produced by resonance of ventricular blood, myocardium, and the atrioventricular valve ring.

The first heart sound has four components: residual atrial vibration (Orias, 1936; Braun Menendez and Solari, 1936; Kincaid Smith and Barlow, 1959); a low frequency component immediately after the $Q$ wave of the electrocardiogram (' $M$ ' of Lakier et al., 1970, 1972; ' $O$ ' of Luisada and Argano, 197I); a high frequency component due to tensing of the mitral valve cusps and chordae at the time of the ' $C$ ' wave of the left atrial pressure pulse tracing (' $\mathrm{M}_{1}$ ' of Lakier et al., 1970, 1972); and then sounds attributed to the opening of the semilunar valves and distension of the walls of the great vessels.

The nature of origin of ' $M$ ' is uncertain: it may be due to coaption of the atrioventricular valve cusps (Lakier et al., 1970, 1972), residual atrial vibrations (Orias, 1936; Orias and Braun Menendez, 1939), initial muscular vibrations (Smith, Gilson, and Kountz, I94I; Counihan et al., I95I; Luisada and Argano, I97I), and tricuspid valve closure (Hultgren and Hubis, 1965).

We have studied the low frequency vibration ' $M$ ' in health, in patients with mitral incompetence, and after replacement of the mitral or mitral and tricuspid valves both in the presence of sinus rhythm and of atrial fibrillation. In order to identify its nature and cause, 53 patients were studied and the results are analysed.

\section{Patients and methods}

The nature of ' $M$ ' was studied in 53 patients (Table $I$ ). Nine subjects had a normal heart, 6 had isolated mitral Received 7 December 1972.

1 Supported by a grant from the Anglo American Corporation of South Africa. incompetence, and in 38 the mitral valve had been replaced by an artificial prosthesis (20 with a StarrEdwards prosthesis, Io with a Beall prosthesis, and 8 with a mounted inverted aortic valve homograft). In 3 patients both mitral and tricuspid valves had been replaced. Twenty patients studied after valve replacement were in atrial fibrillation.

Recordings were made on two different recording systems. A Sanborn photographic Twin Beam recorder was used with a Hewlett Packard 21050B microphone and 1506A heart sound amplifier with signal splitter to permit simultaneous registration of the low frequency apical phonocardiogram and kinetocardiogram. In some patients a Hewlett Packard linear apex cardiogram (2I05ID) was also used. Simultaneous stethoscopic or logarithmic phonocardiogram and an electrocardiogram, or two phonocardiogram tracings, one from the apex and one from the tricuspid area, were recorded. The frequency response of the displacement microphone and recorder was 0.02 to $2000 \mathrm{~Hz}$ and the time constant was 50 seconds. The paper speed was $75 \mathrm{~mm} / \mathrm{sec}$.

TABLE I ' $M$ ' recorded in 53 patients

\begin{tabular}{lr} 
Normal hearts & 9 \\
Mitral incompetence & 6 \\
Starr-Edwards mitral valve replacement & 20 \\
Beall mitral valve replacement & 10 \\
Homograft mitral valve replacement & 8 \\
\hline Total & 53
\end{tabular}

Thirty-eight patients were studied after valve replacement: 20 in sinus rhythm and 18 in atrial fibrillation. 
The Hewlett Packard system provided only two channels of information, and duplicate determinations were made on many of the patients with a DRI6 Electronics for Medicine 16 channel recorder and a contact microphone which registered sounds and displacement simultaneously. Recordings were made at a paper speed of 100 and $200 \mathrm{~mm} / \mathrm{sec}$. The frequency response of the phonocardiographic system was 50 to $2000 \mathrm{~Hz}$, and of the displacement system 0.1 to $30 \mathrm{~Hz}$. The time constant of the displacement system was 2 seconds.

\section{Results}

' $M$ ' in normal subjects and patients with mitral incompetence

Studies were undertaken to show the presence and timing of the sound and to relate this to recordings of other workers (Orias and Braun Menendez, 1939; Rappaport and Sprague, 1942; Counihan et al., 195I; Smith et al., 194I; Kincaid Smith and Barlow, 1959; Lakier et al., 1970, 1972; Luisada and Argano, 1971).

' $M$ ' was identified in every subject. It occurred synchronously with, or occasionally fractionally after, the first movement of the apical kinetocardiogram, about 20 milliseconds after the $Q$ wave of the electrocardiogram and in close relation to the peak of the $R$ wave (Fig. I). It had a natural frequency of $30-50 \mathrm{~Hz}$ and could be distinguished from ' $\mathrm{M}_{1}$ ' which had a higher frequency and greater amplitude. In normal subjects ' $M$ ' was of low amplitude and had a duration of 20 to $50 \mathrm{msec}$. It sometimes continued after the peak of the $R$ for $20 \mathrm{msec}$.

' $M$ ' was also present in all 6 patients with severe mitral incompetence and in 2 cases it was of large amplitude (Fig. 2).

Table 2 summarizes the published characteristics of ' $M$ ' and shows that they correspond with our findings. ' $M$ ' corresponded to the earliest movement of the apical kinetocardiogram, and this became the most useful reference tracing for its identification.

\section{' $M$ ' after mitral valve replacement}

' $M$ ' was identified in every patient in whom the mitral valve had been replaced by a homograft or caged metallic prosthesis. It was a low frequency apical vibration which followed the $Q$ wave of the electrocardiogram close to the peak of the $R$ wave. It coincided with the first movement of the cardiac apical impulse and, in patients with a caged prosthesis, often continued for about $20 \mathrm{msec}$ as a series of short vibrations before the closing click (Fig. 3, 4 , and 5). ' $M$ ' was maximal at the apex and attenuated elsewhere.

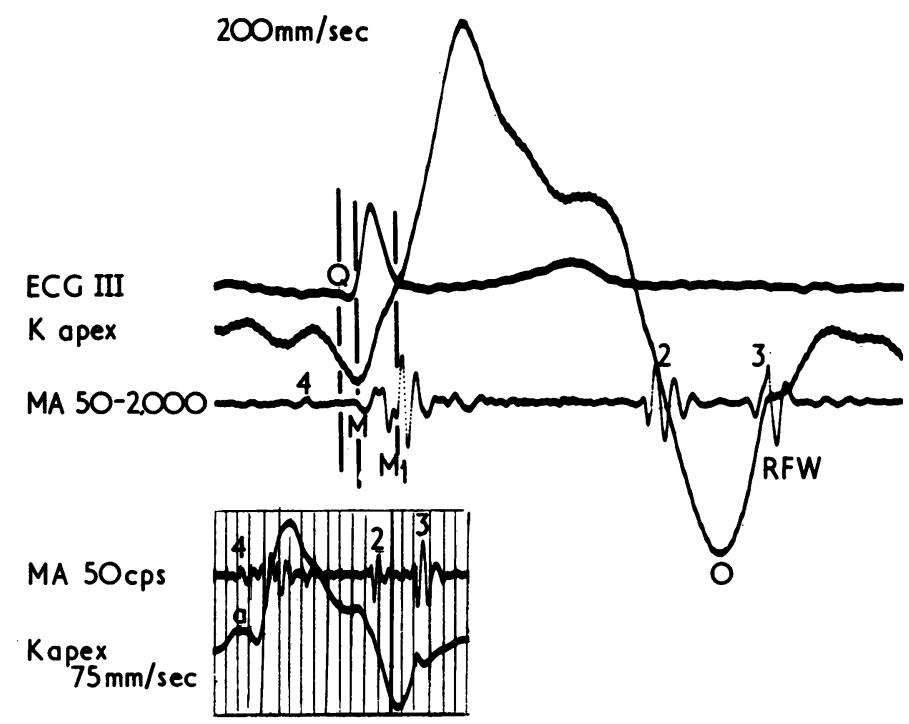

FI G. I Normal youth, aged I6, left lateral position. ' $M$ ' is distinguishable from $S_{4}$ and from $M_{1}$ and is synchronous with the onset of the upstroke (outward movement) of the apical kinetocardiogram ( $K$ apex) in both tracings. The deflection of ' $M$ ' occurs after $Q$, and has a small upward and a large downward deflection. (Electronics for Medicine recorder with tracing recorded at $200 \mathrm{~mm} / \mathrm{sec}$. Inset: Sanborn Twin Beam recorder at $75 \mathrm{~mm} / \mathrm{sec}$ for comparison with later graphs.) 


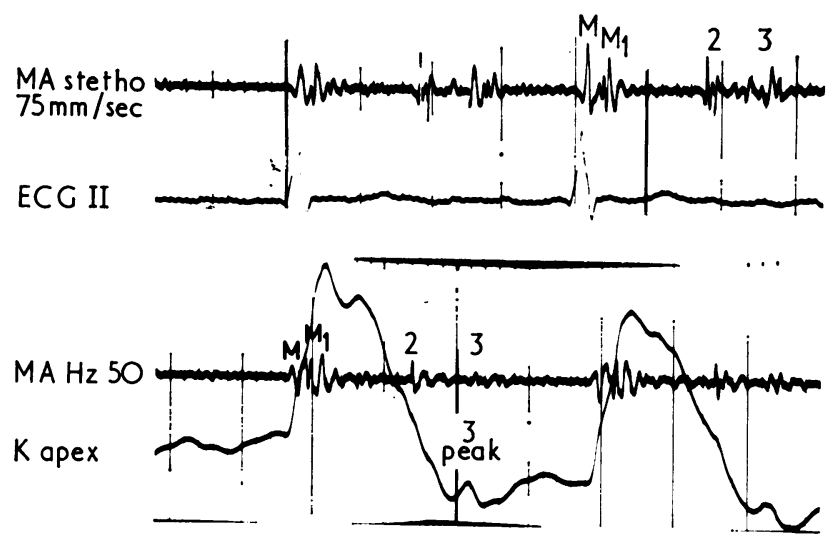

FIG. 2 Patient with mitral incompetence and atrial fibrillation. Two separate phonocardiograms with an electrocardiogram and apical kinetocardiogram as reference tracings. ' $M$ ' is synchronous with the onset of the upstroke of the apical kinetocardiogram (K apex) and its peak follows the $R$ wave.

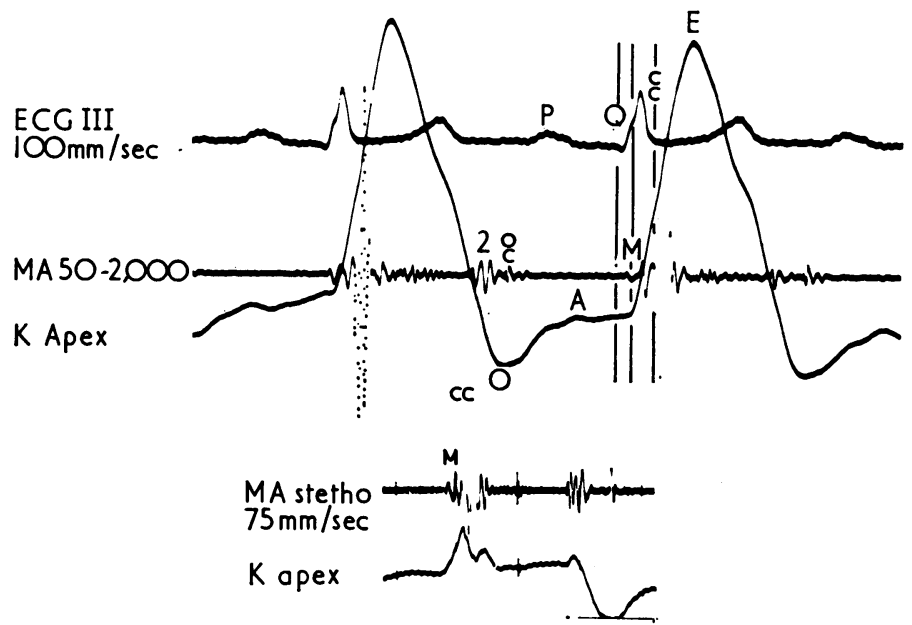

FIG. 3 ' $M$ ' after Starr-Edwards mitral valve replacement. The patient is in sinus rhythm. ' $M$ ' starts with the upstroke of the kinetocardiogram and shows at least two low frequency vibrations before the onset of the high frequency, high amplitude vibrations of the closing click $(C C)$. It starts after $Q$, on the upstroke of $R$, and is easily distinguishable from $C C$ in both tracings. OC is the opening click of the prosthesis. Recordings are made on the Electronics for Medicine recorder $(100 \mathrm{~mm} / \mathrm{sec})$ and the inset on a Sanborn Twin Beam recorder $(75 \mathrm{~mm} / \mathrm{sec}$.)

In stethoscopic or low frequency phonocardiograms ' $M$ ' was prominent and often rivalled aortic closure in amplitude. Table 3 analyses the relation of the amplitude ' $M$ ' in the apical phonocardiogram to the amplitude of aortic closure in patients with a prosthetic valve. Half of the patients with a prosthesis had loud ' $M$ ' vibrations in comparison to 2 of the 9 normal subjects.

' $M$ ' was an audible event and altered the auscultatory character of the first heart sound. The closing click of the prosthesis, well heard in the tricuspid and pulmonary areas, was often masked or enveloped by the preceding low frequency sound at the apex in contrast to the high pitched or clicking quality of the apical opening sound of the StarrEdwards ball.

These studies demonstrate that the same low frequency apical vibration (' $M$ ') can be recorded in normal subjects and in patients after replacement of the mitral valve with a prosthesis. 
TABLE 2 Published characteristics of ' $M$ '

\begin{tabular}{|c|c|c|c|c|c|}
\hline Authors & $\begin{array}{l}\text { Onset } \\
\text { after } Q \\
(m s e c)\end{array}$ & $\begin{array}{l}\text { Frequency } \\
\quad(\mathrm{Hz})\end{array}$ & $\begin{array}{l}\text { Duration } \\
\text { (msec) }\end{array}$ & $\begin{array}{l}\text { Relation to } \\
R \text { peak }\end{array}$ & $\begin{array}{l}\text { Relation to onset apex cardiogram } \\
\text { upstroke }\end{array}$ \\
\hline $\begin{array}{l}\text { Orias and Braun Menendez (1939) } \\
\text { Rappaport and Sprague (1942) }\end{array}$ & Just after & 30 & 38 & $\begin{array}{l}8 \text { msec before } \\
\text { Before } R \text { peak }\end{array}$ & \\
\hline $\begin{array}{l}\text { Counihan et al. (195I) } \\
\text { Tavel (1967) }\end{array}$ & & 35 & 50 & Close & $\begin{array}{l}\text { Coincides or immediately succeeds } \\
\text { Coincides or occasionally } \\
\text { immediately precedes }\end{array}$ \\
\hline $\begin{array}{l}\text { Lakier et al. (1970, 1972) } \\
\text { Luisada and Argano (1971) } \\
\text { Present authors }\end{array}$ & & & & $\begin{array}{l}\text { Peak } \\
\text { Close }\end{array}$ & \\
\hline Present authors & $15-30$ & $30-50$ & $20-50$ & Close & Coincides or immediately succeeds \\
\hline
\end{tabular}
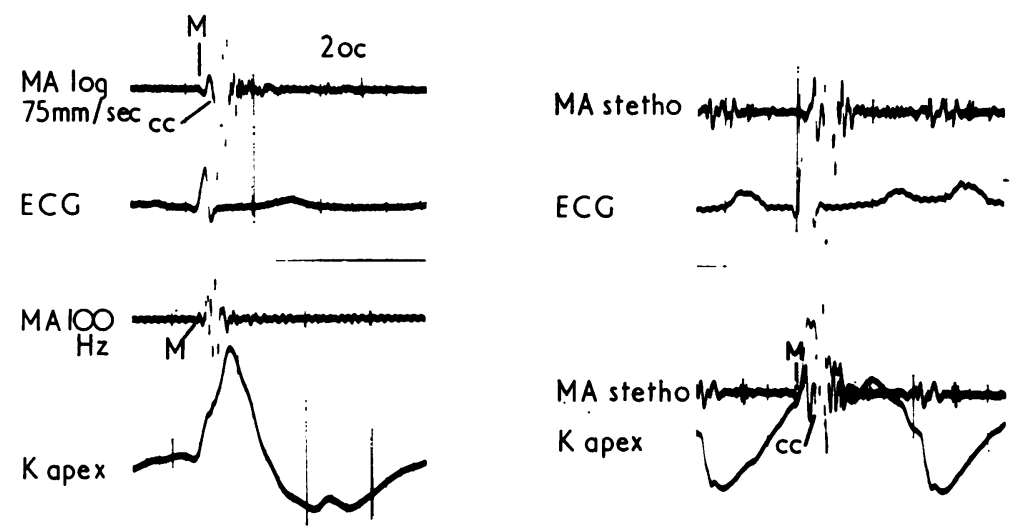

FIG. 4 Tracings from two different patients after replacement of the mitral valve with a prosthesis (Starr-Edwards and Beall). The patients are in sinus rhythm and the phonocardiogram is compared with separate electrocardiogram and kinetocardiogram reference tracings. The peak of ' $M$ ' follows immediately after the peak of the $R$ wave and its onset is synchronous with the onset of the upstroke of the kinetocardiogram in both patients. (Sanborn Twin Beam recorder - paper speed $75 \mathrm{~mm} / \mathrm{sec}$.)

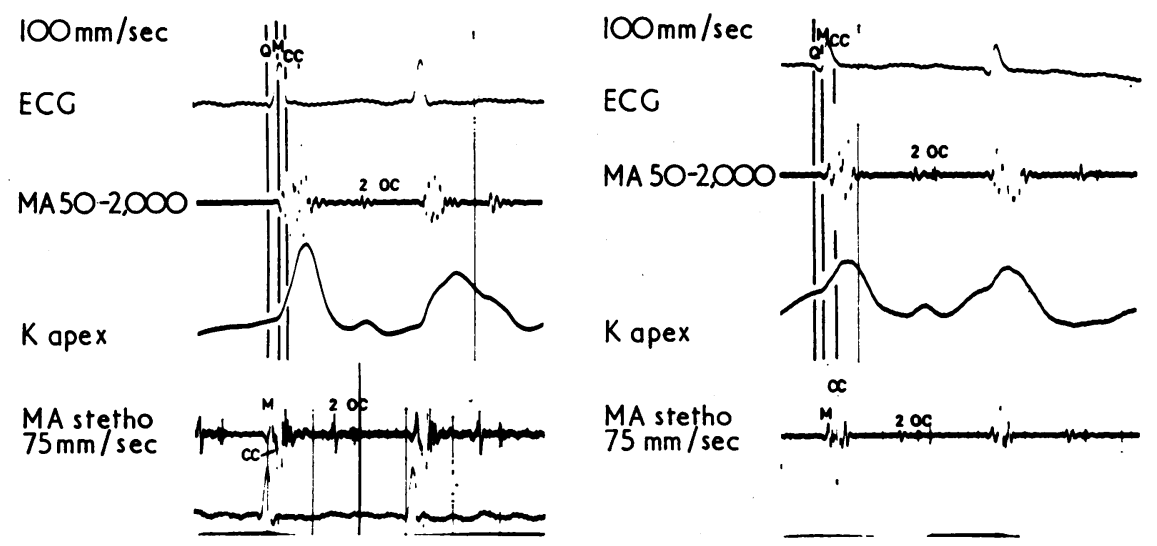

FIG. 5 ' $M$ ' in two patients after mitral valve replacement with a Beall prosthesis. Both patients are in atrial fibrillation. ' $M$ ' is best shown on the lower tracings and is clearly distinguishable from the closing click (CC). In each tracing, ' $M$ ' is equal to aortic valve closure in amplitude. (Upper tracing: 3 channel recording on Electronics for Medicine recorder at $100 \mathrm{~mm} / \mathrm{sec}$. Lower tracing: Sanborn Twin Beam recorder at $75 \mathrm{~mm} / \mathrm{sec}$.) 


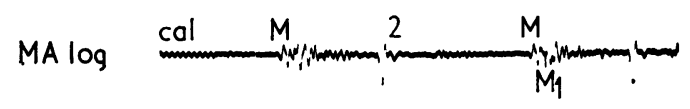

TA log
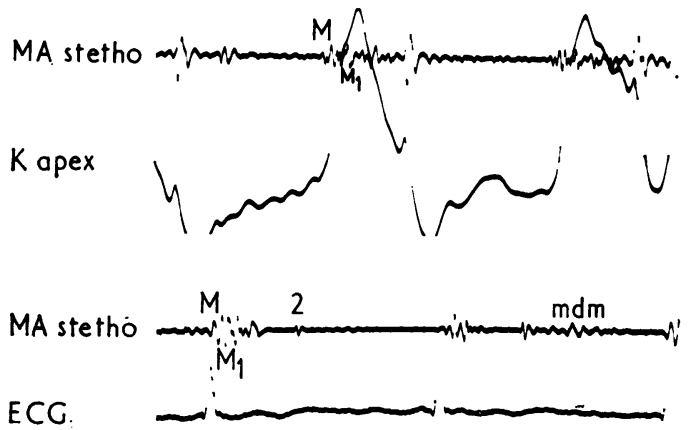

(a)

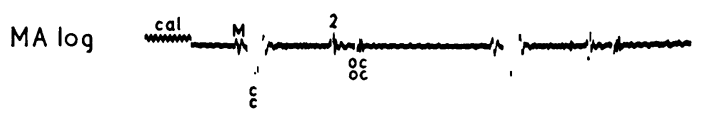

TA log
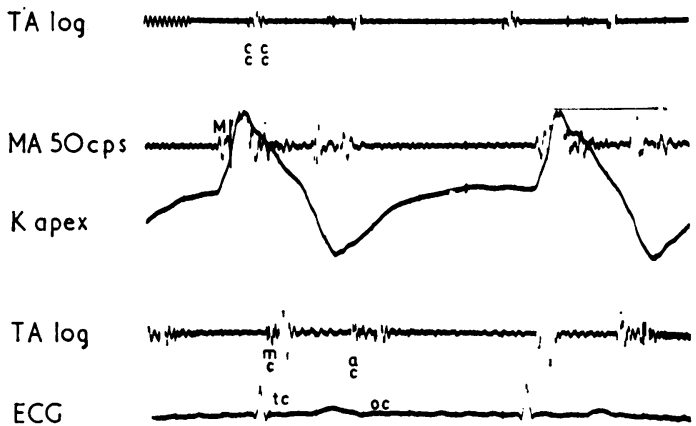

(b)

FIG. 6 ' $M$ ' after replacement of the mitral and tricuspid valve. Separate apical phonocardiograms recorded with tricuspid area phonocardiogram, kinetocardiogram, and electrocardiogram respectively. Paper speed $75 \mathrm{~mm} / \mathrm{sec}$. (a) Tracings recorded in a patient in whom mounted aortic homografts had been used to replace the mitral and tricuspid valves. The patient is in atrial fibrillation. ' $M$ ' is synchronous with the upstroke of the kinetocardiogram and appears after the onset of the $Q R S$. ' $M$ ' is seen at the mitral but not in the tricuspid area. (b) Similar tracings after replacement of the mitral and tricuspid valves with a Beall prosthesis. Patient in atrial fibrillation. ' $M$ ' has the same characteristics as in Fig. 6 a but closures of the mitral and tricuspid prostheses are identifiable and distinct from ' $M$ '. Calibration curves (cal) show comparable gain but slightly higher in the tricuspid area.
TABLE 3 Relative amplitude of ' $M$ ' compared to $A_{2}$ in stethoscopic phonocardiograms taken at mitral area

\begin{tabular}{llllc}
\hline & $\begin{array}{l}\text { Smaller } \\
\text { than } A_{2}\end{array}$ & $\begin{array}{l}\text { Similar } \\
\text { to } A_{2}\end{array}$ & $\begin{array}{l}\text { Much } \\
\text { larger } \\
\text { than } A_{2}\end{array}$ & $\begin{array}{l}\text { Total } \\
\text { no. of } \\
\text { patients }\end{array}$ \\
\hline Normal valves & 7 & 2 & 0 & 9 \\
Mitral incompetence & 4 & 2 & 0 & 6 \\
Hammersmith & 1 & 0 & 0 & I \\
Starr-Edwards & 8 & 7 & 5 & 20 \\
Beall & 3 & 3 & 4 & 10 \\
Homograft & 5 & 2 & 1 & 8 \\
\hline
\end{tabular}

\section{' $M$ ' in atrial fibrillation}

' $M$ ' was present in all the patients who were in atrial fibrillation and two examples are shown in Fig. 5 of patients in whom the mitral valve had been replaced with a prosthesis. The intensity of ' $M$ ' varied from beat to beat. The presence of ' $M$ ' in patients who are in atrial fibrillation excludes atrial contraction as a cause of these vibrations.

\section{' $M$ ' after mitral and tricuspid valve replace- ment}

' $M$ ' persists after replacement of the mitral and tricuspid valve. In Fig. 6 are shown simultaneous phonocardiograms from 2 patients. Each patient had a low frequency sound preceding valve closure or the closing click of the prosthesis. This low frequency sound was present in the mitral area but absent in the tricuspid area. As both mitral and tricuspid closing clicks were present and identifiable, and since both valves had been replaced, the preceding low frequency sound could not have been due to tricuspid valve closure.

\section{Discussion}

' $M$ ' may be a consequence of valve coaption, tricuspid valve closure, residual atrial vibrations, or initial ventricular activity.

' $M$ ' cannot be due to coaption of the atrioventricular valve margins. It is present in patients with prosthetic heart valves in whom the cusp and chordal mechanism have been excised.

The published reports on the phonocardiography of prosthetic valves are scanty and little mention is made of these low frequency vibrations. Gianelly, Popp, and Hultgren (1970) agree that after homograft replacement of the mitral valve, the initial low frequency vibration is synchronous with the onset of praecordial motion. In their figures, large low frequency vibrations are shown without comment, 
$40 \mathrm{msec}$ after the $\mathrm{Q}$ wave, while the two major components of the first sound are shown and stated to occur 70 to $100 \mathrm{msec}$ after Q. Hultgren and Hubis (1965) show the same low frequency vibrations in their tracings after replacement of the mitral valve by a Starr-Edwards prosthesis and attribute them to tricuspid valve closure which they identified before and after operation.

We have shown that ' $M$ ' is present after replacement of both the mitral and tricuspid valves with a prosthesis each of which makes an identifiable sound on closure. ' $M$ ' occurs as an early, separate, and discrete apical sound and cannot be due to tricuspid valve closure.

Kincaid Smith and Barlow (1959) showed an atrial component of the first heart sound in abnormal hearts. In some normal subjects, they showed a low frequency component which resembled ' $M$ ' and which did not change on carotid sinus pressure. They concluded that this could not be due to atrial activity. We have demonstrated ' $M$ ' in atrial fibrillation; atrial contraction or activity, therefore, cannot be the cause of the sound.

The onset of muscular activity of the ventricle is the most tenable explanation of ' $M$ '. This is an old idea. Wollaston (1810, quoted by Orias and Braun Menendez, 1939) showed that the first heart sound would remain audible if atrioventricular valve closure was prevented by obstruction with a finger. Smith et al. (194I) showed that the low frequency vibrations which occurred in the dog heart were not abolished by occluding the venae cavae, by tensing a ligature around the atrioventricular sulcus, or by inflating balloons in the ventricular cavities. Muscular sounds were recorded and heard as long as the vigour of myocardial contraction was maintained. Others have also produced experimental evidence in favour of muscular activity as the cause of this sound, provided a critical amount of shortening is allowed (Eckstein, 1937).

The mechanism and nature of the sound produced by muscular action is uncertain since it occurs during isometric contraction, when there is very little friction of fibres moving on each other. ' $M$ ' occurs at the beginning of isovolumic contraction, during the earliest rounding up phase or 'Umformungzeit' (Holldack, 195I) in which no true fibre movement takes place. This is the brief period when diastolic inflow is checked and the rate of rise of pressure abruptly accelerates. The change in momentum may cause resonance of the blood in the ventricle, the myocardium, and the fibrous skeletal structures of the atrioventricular ring. If this is so, it would resemble the mechanism of the third heart sound. Moreover, when such resonance occurs in a solid metal ring of a prosthetic valve, it may produce a sound which is louder than in normal subjects.

Our acknowledgements to Dr. S. Disler, Medical Superintendent of Wentworth Hospital, for permission to publish, and also to Miss K. Purdon and Mr. R. Taylor for diagrams and photography.

\section{References}

Braun Menendez, E., and Solari, L. A. (1936). Estudio del ruido auricular en el bloqueo auriculo-ventricular experimental. Revista de la Sociedad Argentina de Biologia, 12, II2.

Counihan, T., Messer, A. L., Rappaport, M. B., and Sprague, H. B. (I95I). The initial vibrations of the first heart sound. Circulation, 3, 730.

Eckstein, R. W. (1937). Sounds due to muscular contraction and their importance in auscultatory qualities of the first heart sound. American fournal of Physiology, 118, 359.

Gianelly, R. E., Popp, R. L., and Hultgren, H. N. (1970). Heart sounds in patients with homograft replacement of the mitral valve. Circulation, 42, 309.

Holldack, K. (195I). Die Bedeutung der Umformungs und Druckanstiegszeit fur die Herzdynamik. Deutsche Archiv für klinische Medizin, 198, 7I.

Hultgren, H. N., and Hubis, H. (1965). A phonocardiographic study of patients with the Starr-Edwards mitral valve prosthesis. American Heart fournal, 69, 306.

Kincaid Smith, P., and Barlow, J. (1959). The atrial sound and the atrial component of the first heart sound. British Heart fournal, 21, 470.

Lakier, J. B., Fritz, V. U., Pocock, W. A., and Barlow, J. B. (I970). The left sided components of the first heart sound. South African fournal of Medical Sciences, 35, 85.

Lakier, J. B., Fritz, V. U., Pocock, W. A., and Barlow, J. B. (I972). Mitral components of the first heart sound. British Heart fournal, 34, 160.

Luisada, A. A., and Argano, B. (1971). The sound of the heart. The initial component of the first heart sound. Chest, 60, 79.

Orias, O. (1936). Registro e Interpretación de la Actividad Cardiaca, 2nd ed. El Ateneo, Buenos Aires.

Orias, O., and Braun Menendez, E. (1939). The Heart Sounds in Normal and Pathological Conditions. Oxford Medical Publications, London.

Rappaport, M. B., and Sprague, H. B. (1942). The graphic registration of the normal heart sounds. American Heart fournal, 23, 591.

Smith, J. R., Gilson, A. S., and Kountz, W. B. (I94I). Studies on the muscular element of the first heart sound. American Heart Journal, 21, 17.

Tavel, M. E. (1967). Clinical Phonocardiography and External Pulse Recording, p. 62. Yearbook Medical Publishers, Chicago.

Requests for reprints to Professor M. S. Gotsman, Cardiac Unit, Wentworth Hospital, P. B. Jacobs, Durban, Natal, South Africa. 